\title{
S55-02
}

\section{HOW TO DEVELOP AND IMPLEMENT RECOMMENDED GUIDANCE FOR EUROPEAN PSYCHIATRY?}

\section{W. Gaebel}

Department of Psychiatry, Heinrich-Heine-University Duesseldorf, Duesseldorf, Germany

One of the concrete projects resolved at the 2nd EPA European Platform of Psychiatrists meeting in Nice 2008 concerns the development and implementation of evidence-based treatment recommendations in psychiatry with an European dimension named 'Recommended Guidance'. The major objective is to improve quality of mental health care in Europe by providing evidence-based information and advice regarding core clinical questions and to identify and minimize health care gaps. As following steps it was targeted to establish a steering committee, to obtain clinical core priorities by contacting national psychiatric societies, to provide examples of good practice based on existing information, and to develop (first) 'recommended guidance' for selected topics as pilot work. To promote this process, information regarding existing guidelines in psychiatry, methodological aspects of their development and evaluation as well as implementation strategies will be provided. 